\title{
VAIKŲ VASAROS LAISVALAIKIO SOCIALINĖS, EDUKACINĖS, KULTŪRINĖS PRASMĖS (TEORINIS ASPEKTAS)
}

\author{
Rūta Šiaučiulienė \\ Šiauliu universitetas, Lietuva
}

\begin{abstract}
ANOTACIJA
Remiantis teorine mokslinès literatūros analize, metaanalize, straipsnyje nagrinėjami vaikų vasaros laisvalaikio socialiniai, edukaciniai, kultūriniai ypatumai. Nurodomas šių kontekstų turinys, atskleidžiantis vaikų socialinių, kognityvinių, rekreacinių galimybių raiškos sąlygas ir naujų socialinių vaidmenų igijimą. Analizuojamos vaikų vasaros laisvalaikio prasmingumo nuvertinimo prielaidos.
\end{abstract}

Raktažodžiai: vaikų laisvalaikis, neformali ugdymo(-si) aplinka, socializacija.

\section{IVADAS}

Vaikų vasaros laisvalaikis, kaip neformali socialinè, edukaciné, kultūrinè socializavimosi aplinka, Europoje ir Jungtinèse Amerikos Valstijose yra tokia pat svarbi, kaip ir mokymasis formalioje institucinėje (mokyklinëje) aplinkoje. Šiose šalyse yra domimasi vaikų savaitgalių, švenčių ir mokyklinėmis (tarp jų ir vasaros) atostogomis, laisvalaikiu. Lietuvoje yra atvirkščiai domimasi formaliu laisvalaikiu mokykloje, o vaikų laisvalaikis neformalioje kultūrinėje aplinkoje (juk viena iš tokių aplinkų yra būtent vasaros laisvalaikis) yra beveik netirtas. Vaikų vasaros atostogos darosi aktualios dėl savo ilgos trukmės - du / trys mėnesiai. Dažniausiai tėvų ir vaikų vasaros atostogu trukmè nesutampa, dėl to suaugusiesiems atsiranda naujų rūpesčių dèl vaikų užimtumo vasaros atostogų metu. Kaip tik tuomet vaikų vasaros laisvalaikis yra ir nuvertinamas, suvokiamas kaip suaugusiujų kontroliuojama, planuojama veikla.

Vaiku vasaros laisvalaikis priklauso patiems vaikams, o ne suaugusiesiems. Jis svarbus socialine, kultūrine ir edukacine prasme. Vaikai tampa kiemo, regiono, bendrijų nariais. Anksčiau buvusi formali mokyklinė aplinka keičiasi i laisvą (kiemo, namų, regiono, kaimo / miesto; suaugusiujų, bendraamžiu). Keičiasi ir vaikų vaidmenys: nuo - formalių (mokyklos mokinio, klasės draugo) i neformalius (šeimos vaiko, kiemo, žaidimų, laisvalaikio draugo ir pan.). Vasaros atostogu metu vaikų gyvenimas darosi mažiau reglamentuotas, nedirektyvus, yra veikiamas namų, vietovės (kaimo, miesto), regiono aplinkos, gyvenimo jose tradicijų. Todèl tiek vaiku laisvalaikis, tiek ju užimtumas vasaros atostogu metu yra kitoks, nei mokantis mokykloje.

Tyrimo tikslas - pagrissti vaikų vasaros laisvalaikio socialinę, edukacinę ir kultūrinę prasmę.

Tyrimo objektas - vaikų vasaros laisvalaikis.

\section{METODIKA}

Teorinė mokslinès literatūros analizè, metaanalizè pasirinkta norint atskleisti vaikų vasaros laisvalaikio socialinę, edukacinę ir kultūrinę prasmę. Šie metodai tinka tokio pobūdžio atliekamiems tyrimams, nes straipsnyje yra pateikiama teorinè analizuojamos problemos prieiga. 


\section{TYRIMO REZULTATAI IR JŲ APTARIMAS}

Vaiku vasaros laisvalaikis kaip neformali kasdienio gyvenimo sritis. Vaiku laisvalaikis skiriasi nuo suaugusiuju, nes jų laisvas laikas yra nuolat legimituojamas ir derinamas su ju užimtumu suaugusiems reikšmingoje veikloje. Taigi mokslininkai (Dattilo, 1999; Stebbins, 1999; Kleiber, 2001) formuluoja išvadą, kad i vaikų laisvalaikio edukacini reikšmingumą žvelgiama ne per vaiko laisvo laiko, bet per jo užimtumo prasmingumą, išbraukiant toki laisvalaikio elementą kaip vaikams prasminga ir i̇domi veikla.

Svarbia tampa dar ir tokia vaikų vasaros laisvalaikio edukacinio, kultūrinio, socialinio prasmingumo nuvertinimo prielaida - tèvai dèl naujų laiko leidimo galimybių ir komunikavimo ¿̇vairovès, vaiku vasaros laisvalaikio negali kontroliuoti taip, kaip buvo iprate tai daryti mokyklinio mokymosi metu. Tiek vaikų laisvas laikas, tiek jų užimtumas turi edukacinių, kultūrinių, socialinių prasmių ir tuo skiriasi nuo suaugusiujų laisvalaikio. Vaikų laisvalaikio edukacinès prasmès supratimas yra imanomas tik suvokus laisvalaikio esmę iš vaikų (rekreacinių, kognityvinių, komunikaciniu) poreikių, o ne suaugusiujų. Suaugusiesiems (tėvams, pedagogams ir kt.) siūloma mokyti vaikus laisvalaikio leidimo kultūros ir tuo tikslu rengti edukacines programas aiškinant, kokių socialinių, kultūrinių ir edukacinių galimybių turi laisvalaikis kaip vaiko gyvenimo bei naujos patirties igijimo sfera. Apibūdinsime vaikų vasaros laisvalaikio socialinị, edukacinị, kultūrinị prasmingumą.

Laisvalaikiu vaikui suteikiama galimybė savarankiškai apsispręsti. Vasarą vaikų ugdymas(-is) vyksta stebint gyvenimą, atrandant jame vaikui reikšmingų problemų ir sėkmingai jas sprendžiant. Vaikų laisvalaikis - tai pedagoginė intervencija $\mathfrak{i}$ jų socialini gyvenimą išsaugant vaikų teisę $\mathfrak{i}$ apsisprendimą. Taip pabrèžiama galimybè išsaugoti vaikų laisvę, nes būtent laisvè vaikams sudaro sąlygas pajausti laisvalaikio kultūrini, kognityvinị, komunikacini, edukacini prasmingumą. G. Kvieskienès (1996) nuomone, vaiko laisvalaikis - tai laikas, kada metu jis gali skirti savo intelektines ir dvasines jègas laisvai pasirenkamai veiklai. Kiti autoriai (Lee et al., 1993) analizuoja laisvalaikio tikslus ir nurodo, kad jie pirmiausia turi būti orientuoti ị: vaikų socialinių kompetencijų ugdymą; santykių su suaugusiaisiais ir bendraamžiais prasmingumą, savęs, kaip socialinio individo, suvokimą laisvoje neinstitucinèje aplinkoje. Taip mokslininkai pabrèžia socialinę, ugdomają laisvalaikio reikšmę, nurodydami toki išskirtini jo bruožą kaip laisva ir neinstitucinè aplinka bei vaiko laisvè būnant joje priimti sprendimus ir pasirinkti laisvalaikio turini ir formas. Be to, Y. Lee ir kt. (1993) teigimu, būtent tokioje aplinkoje vaikai gali ịveikti laisvalaikio organizavimo(si) socialinès patirties stoką. Jie gali bandyti savarankiškai planuoti ir numatyti sąlygas. Vaikų apsisprendimas, kaip leisti laisvalaiki, jiems garantuoja malonų laiko leidimą ir siūlo suaugusiesiems (tėvams ir pedagogams) vaikų laisvalaiki reflektuoti kaip jų igyjamos prasmingo malonumo patirties konteksta.

Vasaros laisvalaikis skatina vaiko tapatybès formavimqsi. Laisvalaikiu vaikai siekia savojo „aš“ itvirtinimo ir nori išsiskirti iš kitų. Todèl ši sieki suaugusieji turètų skatinti ir palaikyti, nes tik tokiu atveju vaikai galès jaustis saugūs ir laisvi. Laisvalaikiu taip pat ugdomos ir vaiku lyderiavimo savybès. Vaikų pomėgių palaikymas laisvalaikiu atveria jiems nauju galimybių socialinei, kognityvinei, komunikacinei, rekreacinei veiklai reikšmingoje aplinkoje. Laisvalaikis skatina vaiko tapatybès formavimąsi. Taigi laisvalaikio tapatumai yra svarbūs asmens savivokai, nes jie 
išreiškia ir patvirtina individo gebejjimus, suteikia socialini pripažinimą. Nurodomas toks pagrindinis laisvalaikio tikslas socialinejje sistemoje - garantuoti tokiq laiko praleidimo kokybę, kad formuotusi kuo ¿̇vairiapusiškesnis vaikas, gebantis integruotis ì visuomenę ir prisitaikyti prie sparčiu nuolatiniu pokyčiu. Suaugusiesiems (tėvams ir pedagogams) sudaroma galimybè suvokti vaiko vasaros laisvalaikio socialinę-kognityvinę esmę ir tuos prioritetus, kuriuos jam suteikia vaikai, o ne suaugusieji.

Vaiku vasaros laisvalaikis - tai organizuota ir neorganizuota veikla. Organizuotas laisvalaikis siauraja prasme - tai popamokinè veikla. Ją pedagogai organizuoja atsižvelgdami i vaikų amžių, poreikius, interesus. Toks organizavimas pratina vaikus naudingai leisti laisvą laiką, tobulèti. Teigiamai vertinamas laisvalaikis, kai vaikas gilinasi $\mathfrak{i}$ kurios nors mokslo, meno, technikos srities dalykus arba kai vaikas sportuoja, keliauja, lanko parodas, spektaklius, skaito knygas, dalyvauja meno saviveikloje. K. Silbereisen ir E. Todt (1994) nurodo, kad dalyvavimas ivvairių būrelių, klubų veikloje leidžia vaikams demonstruoti tai, ką jie geba, ir sudaro prielaidas būti pozityviai suaugusiujuc ịvertintais. Mokslininkų nuomone, visa tai skatina vaiko pasitikejjimą savimi, ugdo teigiamą požiūri i darbą, skatina norą tobulèti, ieškoti prasmingų laisvalaikio leidimo būdų. Šie mokslininkai nurodo, kad neorganizuotas laisvalaikis gali neigiamai veikti vaikus, ypač tais atvejais, kai jie renkasi laisvalaikio formas atsižvelgdami i bendraamžių nuomonę, o ne i savo poreikius ar interesus.

Vasaros laisvalaikiu vaikai gali pailsèti, atsipalaiduoti nuo mokyklinio mokymosi, namu ruošos darbu ir igauti jëgu. „Dabartinès lietuvių kalbos žodyne“ (2000) laisvalaikis yra aiškinamas kaip laisvas nuo darbo laikas. Laisvalaikis apibūdinamas kaip žmogaus/vaiko ne darbo laiko dalis, skirta laisvai pasirenkamai veiklai, kuri paprastai padeda atgauti jègas (Blaževičius, 2006). I vaikų laisvalaikio turini neįeina namu ruošos, fiziologinių poreikių tenkinimo laikas. L. Kublickienè (2001) pateikia dvi skirtingas laisvalaikio traktavimo paradigmas: tradicine ir socialinę-ekonominę, laisvalaiki apibrèžiančias kaip laisva laikq nuo mokamo darbo, buitiniu ir fiziologiniu poreikiu tenkinimo: socialinę-psichologine, laisvalaiki ịvardijančią kaip tam tikrq žmogaus dvasinę būsena, kuriq nusako individualūs suvoktos laisvès, vidinio pasitenkinimo, teigiamu jausmu išgyvenimai. Bandoma parodyti, kad laisvalaikis yra labiau subjektyvus ir psichologinis konceptas.

Vaiku vasaros laisvalaikis - viena svarbiausiu socialiniu vertybiu. Vertybès paprastai formuojasi vaiko socializavimo(-si) procese igalinant ir jas perimant iš socialinès aplinkos, šeimos ir visuomenines (Kleiber, 1999). Vaiko asmeninès vertybinès orientacijos/nuostatos rodo, kaip ir su kuo jis yra linkęs leisti laisvą laiką. Kiekvienas vaikas turi asmeninę laisvalaikio būdų pasirinkimo teisę, kuria išreiškia savo valią, parodo požiūrį i vertybes ir i̇ bendrą vidinę kultūrą. Vasaros laisvalaikiu vaikas ugdosi ir socialine atsakomybę: kuo atsakingiau ir prasmingiau jis leidžia laisvalaiki (derindamas užimtumą su neužimtumu), tuo kryptingiau jis bręsta kaip asmenybe, galinti savarankiškai priimti sprendimus dèl savo veiklos ir büti už juos atsakinga.

Vaiku vasaros laisvalaikis priklauso nuo tam tikru tradiciju ir orientavimo ì vienus ar kitus vaiku užsiemimus. Jeigu orientuojamasi tik i formalaus pobūdžio vaikų mokyklinius užsisèmimus, tai nėra vertinama kaip neformalus vaiko laisvalaikis (Danish et al., 1981). Nurodoma, kad laisvalaiki lemia aplinkybės ir veiksniai, kurie savo esme yra objektyvūs (suaugusiujų laisvalaikis, šeimos ekonominè gerovė ir pan.). Visgi vaikų laisvalaikis pirmiausia priklauso būtent nuo to, kaip 
suaugusieji suvokia jo esmę ir kaip jie bando ieškoti naujų vaiko saviraiškos galimybių. Nuo suaugusiujų (tėvų, pedagogu ir kt.) požiūrio i laisvalaiki ir apskritai i vaikų laisvalaikị, kaip specifinę vaikų gyvenimo sritị, priklauso ir visuomenès požiūris į ši reiškinị.

Vaiku vasaros laisvalaikis tai - užimtumo ir neužimtumo derinys; aplinka vaiko, kaip socialinio individo, veiksmu laisvès aplinka (Larson, 2000). Ši samprata prieštarauja suaugusiuju požiūriui i vaikų laisvalaikị, kaip į užimtumą, nes laisvalaikis yra laisvė vaikų veiksmams bei savarankiškiems sprendimams pasirenkant malonumus ir pramogas. J. Pieper (1963) siūlo gilintis i vaikų laisvalaikị šiuolaikinès visuomenès kultūros požiūriu ir atkreipia dėmesị i tokią situaciją: vaikai nuolat užimti, juos slegia rūpestis dèl darbų neužbaigtumo, nes suaugusieji juos nuolat kontroliuoja ir nurodo, ko jie dar nenuveikè ir ką dar turètų nuveikti. Todèl, jo nuomone, vaikų laisvalaiki reikia sieti ir su neužimtumu, nes tai suteikia galimybių igyti ívairesnès gyvenimo patirties, kuriai tiek mažai dėmesio skiriama formalioje institucinèje aplinkoje - mokykloje.

Vaiku laisvalaikiu vyksta ju socialinès, kognityvinès patirties rekonstrukcija, kurios metu atsiranda galimybė atsisakyti tiek iškreiptos nepriklausomybès, tiek ir priklausomybès nuo suaugusiujų. Jos pasekmè - ,vaiko išmoktas bejègiškumas“ (Stebbins, 1999, p. 14). Be to, atsiranda galimybė suvokti veiklos naudingumą kitiems ir realizuoti save svarbioje veikloje.

Vaiku vasaros laisvalaikis - pedagogine intervencija $i$ ju socialini gyvenima, išsaugant vaiku, kaip socialinès grupès, ir vaiko, kaip individo, teisę $\dot{k}$ apsisprendima (Danish et al., 1981). Tokiu būdu pabrèžiamos galimybès išsaugoti vaikų laisvę, nes būtent laisvė vaikams sudaro sąlygas pajusti laisvalaikio kultūrini, kognityvini, komunikacini, edukacini prasmingumą.

Laisvalaikio tikslai turi büti orientuoti i vaiku socialiniu kompetenciju ugdyma; santykiu su suaugusiaisiais ir bendraamžiais prasminguma, savęs, kaip socialinio individo, suvokima laisvoje neinstitucinëje aplinkoje. Tokiu būdu pabrěžiama socialinè, ugdomoji laisvalaikio reikšmè, nurodant išskirtini jo bruožą - laisva ir neinstitucinė aplinka bei vaiko teisė joje priimti sprendimus dèl laisvalaikio turinio, formų. Be to, būtent tokioje aplinkoje vaikai gali įveikti socialinès patirties stoką laisvalaikio organizavimo(-si) srityje. Jie gali bandyti savarankiškai planuoti ir numatyti salygas planui igyvendinti bei prisiimti ivairius vaidmenis - laisvalaikio partnerio, komandos nario ar lyderio.

Vasaros laisvalaikiu vaikai siekia savojo „aš ¿̇tvirtinimo ir nori išsiskirti iš kitu. Taigi ši siekị suaugusieji turètų skatinti ir palaikyti, nes tik taip vaikai galès jaustis saugūs ir laisvi. P. Baltes ir M. Baltes (1990) teigimu, tai yra viena iš svarbiausių sąlygu atsipalaiduoti, būdas fizinėms ir psichinėms jègoms atgauti, kurias vaikai vèliau gali nukreipti $\mathfrak{i}$ formaliają mokymosi veiklą. Šie mokslininkai siūlo sudaryti edukacines programas, formuojančias vaikų supratimą, kad laisvalaikis yra ne tik malonumas, bet ir prasmingi užsièmimai, pastangos bei atsakomybè. Taigi mokslininkai aiškina, kad vaikų laisvalaikio esmės kitoks supratimas atveria naujų galimybių jų saviraiškai. Jų nuomone, laisvalaikis - tai visu pirma vaiku laisvas laikas, kurio metu jie gali tenkinti jvairius poreikius; tai laisva aplinka, kurioje vaikas gali igyti prasmingo laisvalaikio leidimo patirties; laisvalaikiu ugdosi vaiko, kaip asmens, galimybe igytai patirčiai apmastyti; susidaro palankios salygos vaiku socialiniu, kognityviniu ir rekreaciniu galimybiu raiškai ir nauju socialiniu vaidmenu igijimui. 


\section{IŠVADOS IR PERSPEKTYVOS}

Šiandienos visuomenès demokratijos, liberalizavimo procesai deklaruojama humanizmo filosofiją ir leidžia analizuoti vaiku vasaros laisvalaikio kultūra, kaip socialinị edukacini reiškiní. Tuomet vaikų vasaros laisvalaikio kultūra yra iprasmina kaip pačių vaikų disponuojamas laikas, apimantis socialines, edukacines, kultūrines prasmes. Dèl tokios sampratos vaikas tampa aktyvus laisvalaikio kultūros kūrèjas.

Vaikų vasaros laisvalaikio kultūros socialini, edukacinị reikšmingumą galima suvokti iš pačių vaikų suteikiamų prasmių. Būtent tokia interpretacinè vaikų vasaros laisvalaikio kultūros paradigma tampa reikšminga kuriant naujas ugdytojų (tėvų, pedagogu, neformaliojo ugdymo specialistų ir kt.) žinias.

Vaikų neformalios kultūrinės veiklos sritys yra tokios pat svarbios, kaip ir formalios. Jos yra reikšmingos vaikų ugdymui(-si) ne tik savo socialine, edukacine, kultūrine prasme. Tomis naujomis situacijomis atsiranda palankios sąlygos vaiko socializavimuisi ir ugdymuisi, nes jų metu vaikas panaudoja jau turimą patirti, kuria kažką naujo, plėtoja tokias savo patirtis kaip: komunikacinę, kognityvinę, organizacinę, žaidybinę, rekreacinę, verslumo, kasdieniu gyvenimo problemų sprendimo, bendradarbiavimo, gebėjimo prisiimti tam tikrus socialinius vaidmenis, laiko planavimo ir $\mathrm{kt}$.

\section{LITERATŪRA}

1. Baltes, P., Baltes, M. (1990). Psychological Perspectives on Successful Ageing: The Model of Selective Optimization with Compensation. Cambridge: Cambridge University Press.

2. Blaževičius, P. (2006). Laisvalaikio organizavimas. Rokiškis: Igorio Skripkos individualioji įmonè.

3. Dabartinès lietuviu kalbos žodynas. (2000). Vilnius: Mokslo ir enciklopedijų leidybos institutas.

4. Danish, S., Smyer, M., Nowak, C. (1981). Developmental intervention: Enhancing life event processes. Life Span Development and Behavior, 3, 339-366.

5. Dattilo, J. (1999). Leisure Education Program Planning: A Systematic Approach. Venture: State College, PA.

6. Kleiber, D. (2001). Developmental intervention and leisure education: A life span perspective. World Leisure, 1, 4-10.

7. Kleiber, D. (1999). Leisure experience and human development. New York: Basic Books.

8. Kublickienè, L. (2001). Laisvalaikio sociologija: paradigmų skirtumai. Filosofija, sociologija, 2, 35-43.

9. Kvieskienė, G. (1996). Laisvalaikio kultūra (teorija, praktika, rekomendacijos). Vilnius: Vilniaus pedagoginis universitetas.

10. Larson, R. (2000). Toward a psychology of possitive youth development. American Psychologist, 55, $170-183$.

11. Lee, Y., Brock, S., Dattilo, J., Kleiber, D. (1993). Leisure and adjustment to spinal cord injury: conceptual and methodological suggestions. Therapeutic Recreation Journal, 27(3), 200-211.

12. Pieper, J. (1963). Leisure: the Basis of Culture. New York: Random House.

13. Silbereisen, K., Todt, E. (1994). Adolescence in Context. The Interplay of Family, School, Peers, and Work Adjustment. New York: Springer-Verlag.

14. Stebbins, R. (1999). Educating for serious leisure. World Leisure and Recreation, 41 (4), 14-19. 


\title{
SOCIAL, EDUCATIONAL, CULTURAL MEANINGS OF CHILDREN'S SUMMER LEISURE: THEORETICAL ASPECT
}

\author{
Rūta Šiaučiulienė \\ Šiauliai University, Lithuania
}

\begin{abstract}
Research background. Children's summer leisure as non-formal cultural education (learning) environment in Europe and the United States is equally important as learning in a formal, institutionalized (school) environment. In these countries there is interest in children's weekend, festive, school (including summer) vacation, leisure time. Lithuania is the opposite - a formal interest in school, leisure, entertainment and children's informal cultural environment (after all, one of these environments is summer leisure environment) has not been almost studied. Children's summer vacation became important because of its long duration - two / three months. Most parents and children's summer vacation periods do not coincide, so adults worry about their children activity during the summer holidays. Then children's summer leisure is overlooked, perceived as an adult controlled and proposed activity.

The aim of the study is to justify social, educational, cultural meanings of children's summer leisure.

The object of the study is children's summer leisure significance.

Methods: theoretical analysis, meta-analysis.

Results. The processes of democracy and liberalization occurring in modern society and the declared philosophy of humanism permit to investigate children's leisure culture in summer as a social and educational phenomenon within the contexts of 'free' (self-) education and the phenomenon of freedom. Children's leisure culture in summer is contextualized as the time disposed by children themselves and implicates social and educational meanings. In terms of such conceptions the child becomes an active creator of his/her leisure culture. The social and educational significance of children's leisure culture in summer is perceived through the meanings attached by children themselves. Such interpretational paradigm of children's leisure culture in summer turns out to be significant in creating new knowledge for educators (parents, teachers, specialists of non-formal education, etc.). Children's narrative on summer leisure enables this discourse to be accepted in the science of education/pedagogy as overt/main rather than hidden/secondary one, existing alongside with the discourse created by adults 'children are immature sociocultural individuals, therefore, unable to carry out an activity, which is significant for their (self-)education and (self)socialization'.
\end{abstract}

Keywords: children's summer leisure, non-formal education (learning) environment. 


\section{СОЦИАЛЬНЫЕ, ЭДУКАЦИОННЫЕ, КУЛЬТУРНЫЕ СМЫСЛЫ ДЕТСКОГО ЛЕТНЕГО ОТДЫХА: ТЕОРЕТИЧЕСКИЙ АСПЕКТ}

\section{Рута Шяучюлене}

Шяуляйский университет, Литва

\section{PЕЗЮМЕ}

Теоретическое обоснование. Детский летний отдых, как неформальная социальная, эдукационная и культурная социализирующая среда, и в Европе, и в США является не менее важным, чем учеба в формальной, институциональной (школьной) среде. Большое внимание уделяется досугу детей, как они проводят свободное время по выходным, в праздничные и школьные (в том числе и летние) каникулы. В Литве наоборот - больше внимания уделяется формальному досугу в школе, а провождение свободного времени в неформальной культурной среде (в том числе во время летнего отдыха) почти не исследовалась. Летние каникулы детей стали актуальной проблемой из за своей длительности (два три месяца). В большинстве семей продолжительность летних каникул родителей и детей не совпадает, и у взрослых возникают новые заботы по поводу занятости детей во время летнего отдыха. Досуг детей обесценивается, поскольку взрослые этот период воспринимают как ими контролируемую и планируемую деятельность.

Цель исследования - обосновать летний досуг детей в социальном, эдукационном, культурном смыслах.

Объект исследования - смыслы детского досуга во время летних каникул.

Методы: теоретический анализ, метаанализ.

Выводы. Процессы демократии и либерализации, происходящие в современном обществе, декларуемая гумманистическая философия позволяют анализировать культуру детского досуга как социальное, эдукационное явление. Таким образом культура детского летнего досуга воспринимается в контексте свободного времени, которым диспонируют сами дети и которое имплицирует в себе социальные, эдукационные, культурные смыслы. По такому представлению дети становятся активными творцами культуры своего досуга. Социальная и эдукационная значимость летнего досуга воспринимается через смыслы, которые придают сами дети. Именно такая интерпретационная парадигма культуры летнего досуга детей становится значительным фактором в процессе создания новых знаний для родителей, учителей, специалистов неформального воспитания и т. д. и позволяет существовать наряду с дискурсом, созданным взрослыми.

Ключевые слова: детский досуг, неформальная эдукационная среда, социализация. 